\title{
Acidizing of conventional and tight sandstone formation using chelating agents: mineralogical prospect
}

\author{
Mian Umer Shafiq ${ }^{1,2}\left(\right.$ ID $\cdot$ Hisham Ben Mahmud ${ }^{2} \cdot$ Sophia Nawaz Gishkori ${ }^{3} \cdot$ Kiat Moon Lee $^{4} \cdot$ Reza Rezaee $^{5}$
}

Received: 3 February 2020 / Accepted: 15 June 2020 / Published online: 30 June 2020

(c) The Author(s) 2020

\begin{abstract}
Stimulation of the sandstone reservoir requires a mixture of acids such as mud acid, which assist in enlarging the microscopic paths by dissolving the siliceous fines or clays near the well-bore region. As a result, the formation permeability and porosity can be enhanced. In deeper wells, the temperature exceeds $200^{\circ} \mathrm{F}$, at these temperature ranges, problems can arise. For example, the use of mud acid mixtures can lead to issues like precipitations, corrosion, early consumption of acids, leading to lesser acid efficiency. In this study, the core flooding apparatus was used for acidizing experiments, designed to dissolve minerals and to analyze the changes in petrophysical parameters such as porosity, permeability, and mineralogy. Conventional and tight sandstone core samples were acidized using different chelating acids such as Hydroxyethylethylenediaminetriacetic acid (HEDTA), Ethylenediaminetetraacetic acid (EDTA) and Glutamic acid (GLDA) at high-temperature conditions. Analytical studies (mineral mass, pore size distribution, topology, grain size distribution, and density distribution were conducted using Tescan Integrated Mineral Analysis (TIMA). The obtained results showed that chelating agent HEDTA created more pore spaces in the core samples and is effective in dissolving positive ions. Also, the permeability was observed to be doubled by its application which could be effective in alteration of pore topology of the sandstone cores.
\end{abstract}

Keywords Stimulation $\cdot$ Mineralogy $\cdot$ Chelating agent $\cdot$ Sandstone $\cdot$ Petrophysical

\section{Introduction}

Sandstone is a clastic sedimentary rock, primarily made up of quartz and minor cementing minerals such as quartz, feldspar, various forms of clays and carbonates (Shafiq et al. 2018c), which can acquaint with severe damage if introduced to incompatible fluids. Sandstone acidizing is a heterogeneous acid-rock process; therefore, the selection of acid mixture is critical. Improper selection of acid and acid treatment will further damage the formation rather than

Mian Umer Shafiq

umer.engr@hotmail.com

1 NFCIET, Multan, Opposite Pak Arab Refinery, Khanewal Road, Multan, Pakistan

2 Curtin University, Malaysia, CDT 250, 98009 Miri, Sarawak, Malaysia

3 University of Gujrat, Gujrat, Pakistan

4 UCSI University, Kuala Lumpur, Malaysia

5 Curtin University Australia, Kent Street, Bentley, WA, Australia improving it, especially in a high-temperature condition in the reservoir (Shafiq and Ben Mahmud 2017).

Illite/smectite, for example, a component of clay, swells when contacted with freshwater and can reduce the permeability and porosity of the rock effectively. Reservoir rocks are stimulated by acid injection below the fracture pressure of the formation. The injection of the acid in the sandstone layers will cause the dissolution of the minerals in the formation, hence increasing the flow rate of the reservoir fluid (Mahmud and Leong 2017; Leong et al. 2018).

Recent technology of matrix acidizing in sandstone formations helps in maintaining and improving hydrocarbon productivity (Shafiq et al. 2018a, b, 2019a, b). It improves the reservoir permeability and intergranular porosity around the well bore through flow and acid reaction with sandstone thus enhancing the flow of hydrocarbons into the well (Nianyin and Zhang 2015). By taking into account the sandstone formation characteristic and properties, an appropriate acid system is required to ensure that the treatment is successful as the performance and function of the acid will affect the stimulation process. 
A common practice in sandstone acidizing treatment is using a conventional mud acid system such as hydrochloric acid $(\mathrm{HCl})$ or hydrofluoric acid (HF) in the removal of nearwellbore petrophysical damage. In high-temperature conditions, these mud systems have their shortcomings. $\mathrm{HCl}$ reaction with sandstones at high temperatures affects the stability of clay as well as precipitation of reaction products, which will result in the decrement of porosity and the permeability of the formation (Shafiq et al. 2017). On the other hand, HF encouraged unfavorable sand production (Mahmoud 2017). Problems encountered by HF-based acid systems include limited penetration, severe corrosion, and sludging characteristics especially at high-temperature conditions (Al Mubaraq et al. 2017).

Studies on chelating agents are widely done to solve the shortcomings of the conventional acid mud systems. Chelating agents proved to have low sludging tendencies, better dissolving power, highly degradable, and are excellent iron control agents (Shafiq et al. 2019a, b). Chelating agents combine with complex metal atoms, by forming a ligand through the donation of electrons or coordinate bonds. Multiple coordinate bonds formed from a single molecule will form one or more chelate rings or heterocyclic rings ( $\mathrm{Al}$ Mubaraq et al. 2017). Metal ions such as iron, magnesium, calcium, and aluminum found in the minerals of quartz, feldspar, as well as dolomite in the sandstone layers, can form complex metal-chelate.

The chelating agents studied in this paper are Hydroxyethylethylenediaminetriacetic acid (HEDTA), Ethylenediaminetetraacetic acid (EDTA), and Glutamic acid (GLDA). They contain at least one nitrogen group and multiple carboxylic acid functional groups with nitrogen located at the center of the group (Shafiq et al. 2018a, b). Figure 1 shows the molecular structure of HEDTA, EDTA, and GLDA.

The highly stable metal chelate complex can be formed by the sequestration of a chelating agent with metal ions. Type of metal chelate that is combined governed the stability of the chelate. The stability represents the amount of bond strength between the metal ion and the chelating agent.
The more stable compound possesses larger stability constant (Mahmoud 2017). The affinity of the chelate towards a certain cation also described by the chelate's stability. For instance, if there are two cations with less and large stability constant, the chelating agents will sequester with the cation having the largest stability constant first. This sequestration of the metal compound is directly related to the formation of permeability (Mahmoud 2017). The stability constant for EDTA, HEDTA, and GLDA when reacted with magnesium, calcium, barium, iron (II) and iron (III) are listed in Table 1 .

This study investigates the effect of chelating agents' reaction on two different types of sandstone formations, namely conventional sandstone and tight sandstone. The scope of this paper focuses on the changes in the mineralogy of the core samples, permeability, and porosity distribution in both samples before and after reacting with the chelating agents.

\section{Materials and experiments}

\section{Materials}

There were multiple core samples used for the number of core flooding runs for both Berea and Colton Sandstone rocks. The results obtained are the average of all runs. Table 2 presents the properties of core samples, which are used during the research. Berea core samples were bought

Table 1 Stability constant at $77^{\circ} \mathrm{F}$ (Martell et al. 2004; Frenier 2001; Schuler et al. 2002; Kolodynska et al. 2009)

\begin{tabular}{lccc}
\hline Ion & GLDA & HEDTA & EDTA \\
\hline Calcium & 5.9 & 10.4 & 8.7 \\
Magnesium & 5.2 & 7.0 & 8.7 \\
Barium & 3.5 & 6.2 & 7.7 \\
Iron(II) & 8.7 & 12.2 & 14.3 \\
Iron(III) & 15.2 & 19.8 & 25.7 \\
\hline
\end{tabular}

Fig. 1 Chelating agents (HEDTA, EDTA, and GLDA) structure (Mahmoud 2017)
Glutamic acid N, N-diacetic acid (GLDA)

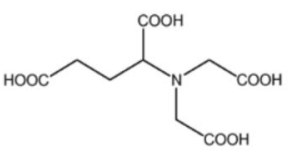

Ethylenediaminetetraacetic acid (EDTA)

Hydroxyethylethylenediaminetriacetic acid (HEDTA)
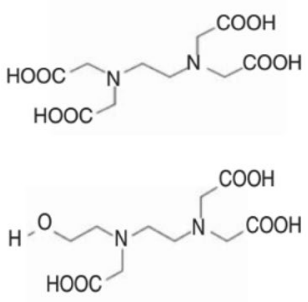
Table 2 Characteristics of core samples used in core flooding experiments

\begin{tabular}{ll}
\hline Berea (conventional sandstone) & Colton (tight sandstone) \\
\hline $\begin{array}{l}\text { Properties } \\
\text { Homogenous }\end{array}$ & Homogenous \\
Clear sandstone & Dirty sandstone \\
Minerals & \\
$93-96 \%$ quartz & $59 \%$ quartz \\
$3-5 \%$ feldspar & $10 \%$ albite \\
& $8 \%$ calcite \\
& $4 \%$ ankerite \\
Porosity & $3 \%$ orthoclase \\
$16-19 \%$ & $10-12 \%$ \\
Permeability & \\
$60-100 \mathrm{mD}$ & $1-2 \mathrm{mD}$ \\
\hline
\end{tabular}

from Vermillion, Ohio, USA while Colton sandstone samples were purchased from Kocurek Industries, Caldwell, Texas, USA. Glutamic acid N, N-diacetic acid (GLDA), Hydroxyethylethylenediaminetriacetic acid (HEDTA), and Ethylenediaminetetraacetic acid (EDTA) were purchased from Chem-Supply where all of them were in powder form with $100 \%$ concentration.

\section{Experiments}

The experiments were performed to study the effects of the chelating agents on both sandstone samples by using customized core flooding apparatus, while the results were measured and recorded using TESCAN Integrated Mineral Analyzer equipment and automated porosity-permeameter.

Major steps performed during the core flooding experiment are as follows:

The core plugs were placed inside the core sleeve, which was then inserted inside the core holder. The inlet and outlet wings of the core holder were then closed. The inlet wing was connected with the flow lines from the injection pump injection at a rate of $1 \mathrm{cc} / \mathrm{min}$.

The syringe pump was connected to the core holder to fill the core with the water. The core plug was then confined to a 1000 psi pressure using a syringe pump. The core holder was then wrapped completely with heating tape and connected to the temperature controller. The temperature and pressure were closely monitored once the heating tape is operated after confining the core sample. The temperature was fixed at $180^{\circ} \mathrm{F}$. The valve was kept open as the expansion of fluid will occur at temperature increment.

The core sample in the core holder was heated for $24 \mathrm{~h}$ before the commencement of acid injection to ensure a wholesome $180{ }^{\circ} \mathrm{F}$ temperature in the system. The acid to be injected was heated to $180^{\circ} \mathrm{F}$ using the magnetic stirrer and heater to maintain an equal temperature between the core sample and the acid.

The pressure transducer used to monitor the pressures at the core holder inlet and outlet was connected to the data acquisition system. By opening the discharge valve of the syringe pump, the core sample was confined. The water flow rate and pressure were selected using the front panel. The system was monitored to ensure there is no leakage at the points of high pressure.

The injected fluid volume was constantly monitored; a decrease in the volume at the outlet was recorded when reacted fluid comes out from the outlet.

Completion of the reaction was noted when constant pressure at the inlet and outlet was achieved. Then, the flow of acid was discontinued, and brine was injected into the core to remove reaction products. The confining pressure was released and the inlet valve switch was turned off once the injection of brine was stopped. Once the reaction is completed, the pump was disconnected, all the parts were cleaned properly and the reacted core sample was put in the oven for $24 \mathrm{~h}$ at $80^{\circ} \mathrm{C}$.

\section{Results}

\section{Porosity}

Table 3 shows the porosity results obtained by AP-608 Automated Porosimeter-Permeameter. HEDTA proved to be efficient in increasing the porosity of Berea sandstone samples where the increment is about $6.8 \%$ from the original porosity followed by GLDA at $5.8 \%$. In the case of Colton formation, EDTA proved to be the best where the porosity increased by $8.5 \%$ followed by HEDTA
Table 3 Initial and final porosity of berea and colton sandstone

\begin{tabular}{|c|c|c|c|c|c|c|}
\hline \multirow{2}{*}{$\begin{array}{l}\text { Chelating agent } \\
\text { reacted }\end{array}$} & \multicolumn{3}{|l|}{ Berea } & \multicolumn{3}{|l|}{ Colton } \\
\hline & initial (\%) & Final (\%) & Changes & initial (\%) & Final $(\%)$ & Changes \\
\hline HEDTA & 19.70 & 21.04 & $6.8 \%$ & 11.74 & 12.49 & $6.4 \%$ \\
\hline EDTA & 19.04 & 19.94 & $4.7 \%$ & 10.74 & 11.65 & $8.5 \%$ \\
\hline GLDA & 19.06 & 20.18 & $5.8 \%$ & 12.38 & 13.12 & $5.9 \%$ \\
\hline
\end{tabular}


where porosity increment is $6.5 \%$. These results will be validated later by permeability and porosity distribution analysis.

\section{Permeability}

The permeability is a very important parameter for the fluid flow. From Table 4, the maximum change in Colton sandstone permeability was observed when HEDTA was applied as the chelating agent. The other two chelating agents showed negative values which may be due to precipitates, residing inside after reaction, blocking the pore throats. However, porosity values initially showed that there is the dissolution of minerals as porosity increased when these chelates applied.

The conducted experiments showed that the increase in porosity and permeability for core samples of both types due to the application of all three chelating agents. HEDTA gives high changes in porosity in the Berea sandstone while EDTA shows a comparatively higher increase in Colton sandstone. Similarly, the core samples' permeabilities increased for all chemical reactions in Berea sandstone with the highest increase in permeability value when GLDA was used. Whereas, there was a decrement in the permeability of Colton sandstone after the reaction with GLDA and EDTA. The decrement in permeability may be due to the precipitation of minerals that reside inside the pore throat during the reaction which caused choking of the tight pore throats.

\section{Integrated mineral analysis}

Field Emission Scanning Electron Microscope (FESEM) was applied to determine mineral, elemental analysis along with the pore size, grain size distribution in the core sample. This technique is high throughput and effective for the analysis of sample mineral composition and morphology. This section explains the results and analyses related to Tescan Integrated Mineral Analysis (TIMA) technology. These results are related to mineral mass, grain size distribution, pore size distribution, panorama, and particle density of the core samples reacted with chelates.

\section{Pore size distribution}

Pore size distribution analysis describes the distribution of different sizes of pores inside the cores before and after the acidizing. It helps to validate the porosity and permeability analyses done before.

\section{Berea}

In the case of Berea sandstone, maximum increment in pore was observed when EDTA was applied as a chelating agent, where the increment in small size pore spaces was $23.3 \%$, followed by HEDTA where the increment was $13.8 \%$ mentioned in Fig. 2. In the case of medium-sized pore spaces, the increment using EDTA was $41.7 \%$, followed by HEDTA where the increment was $22.4 \%$. In terms of large size pore spaces, the maximum increment showed by HEDTA where
Table 4 Initial and final permeability of berea and colton sandstone

Fig. 2 Change in Number of pore spaces (Berea)

\begin{tabular}{|c|c|c|c|c|c|c|}
\hline \multirow{2}{*}{$\begin{array}{l}\text { Chelating } \\
\text { agent reacted }\end{array}$} & \multicolumn{3}{|l|}{ Berea } & \multicolumn{3}{|l|}{ Colton } \\
\hline & initial $(\mathrm{mD})$ & Final $(\mathrm{mD})$ & Changes & initial $(\mathrm{mD})$ & Final $(\mathrm{mD})$ & Changes \\
\hline HEDTA & 165.00 & 166.34 & $0.8 \%$ & 0.5441 & 0.9242 & $69.8 \%$ \\
\hline EDTA & 124.53 & 128.01 & $2.8 \%$ & 0.7840 & 0.6695 & $-14 \%$ \\
\hline GLDA & 80.53 & 86.21 & $7.1 \%$ & 0.9173 & 0.8607 & $-6.1 \%$ \\
\hline
\end{tabular}

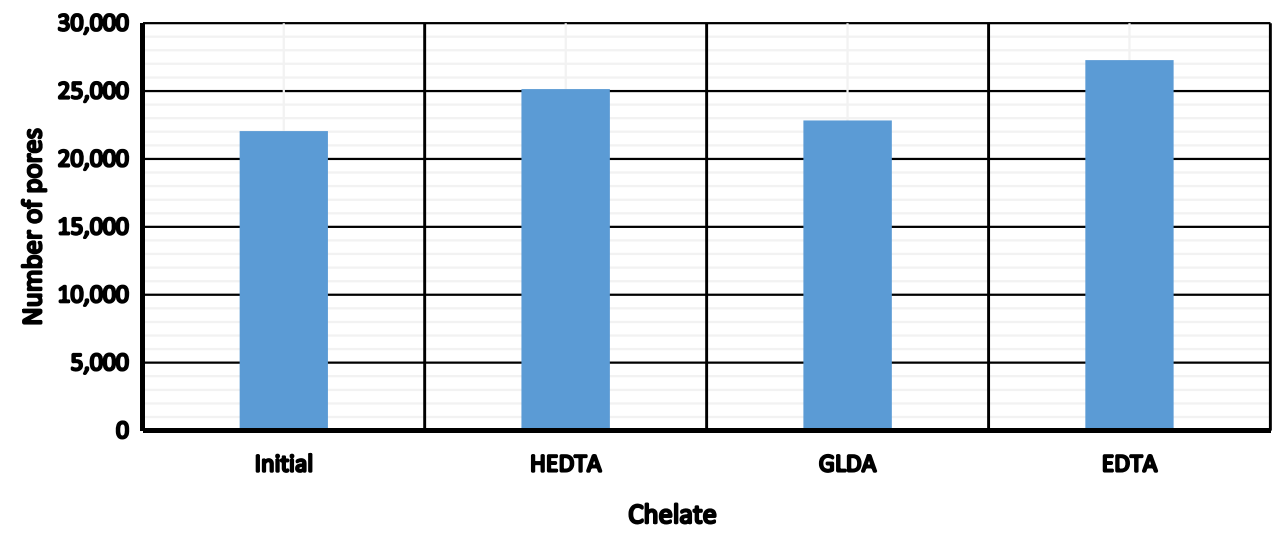


$33.3 \%$ increase was observed followed by GLDA at $20 \%$. While in the case of EDTA, the decrease in this pore size range was observed which could be due to precipitation that resided inside the big pore spaces. The big pore spaces created by HEDTA may be responsible for more porosity increment shown in Table 5.

\section{Colton}

In the case of Colton sandstone illustrated in Fig. 3, the maximum increment was observed, when HEDTA was used, where the increment in small size pore spaces was $8.7 \%$, followed by GLDA where the increment was $6.6 \%$. In the case of medium-sized pore spaces, the increment using EDTA was $61.6 \%$, followed by GLDA where the increment was $59.2 \%$. In terms of large size pore spaces, the maximum increment showed by EDTA where $240 \%$ increase observed followed by GLDA with a $220 \%$ increment as shown in Table 6 . Whereas if overall pore spaces are under consideration, then HEDTA proved to be the best where the increment was $8.6 \%$, while in case of EDTA, decrease observed which can be due to precipitation where precipitates reside inside the small pore space. For EDTA, the overall increase in porosity observed may be due to the increment of large-sized pore spaces.

The pore size distribution shows an overall increase in a number of pores for both core samples, although there is a decrease in overall pore size for Colton sandstone when EDTA was applied. The decrease could also be due to a decrease of the smallest $(9.6-33 \mu \mathrm{m})$ and medium (33-68 $\mu \mathrm{m})$ pore sizes instead of creating new small-sized pores. The increase described the dissolution of minerals in the core samples when reacted with the chelating agent. The increase in the large size pores has tremendously contributed to the overall porosity increment.
Table 5 Initial and final pore size distribution of Berea sandstone

\begin{tabular}{llllllll}
\hline Pore size range $(\mu \mathrm{m})$ & Initial & HEDTA & $\%$ change & GLDA & $\%$ change & EDTA & $\%$ change \\
\hline $9.6-50$ & 21,589 & 24,573 & $13.8 \%$ & 22,299 & $3.2 \%$ & 26,623 & $23.3 \%$ \\
$50-101$ & 450 & 551 & $22.4 \%$ & 521 & $20 \%$ & 638 & $41.7 \%$ \\
$101-150$ & 15 & 20 & $25 \%$ & 18 & $20 \%$ & 13 & $-6.6 \%$ \\
Total & 22,054 & 25,144 & $14 \%$ & 22,838 & $3.5 \%$ & 27,274 & $23.66 \%$ \\
\hline
\end{tabular}

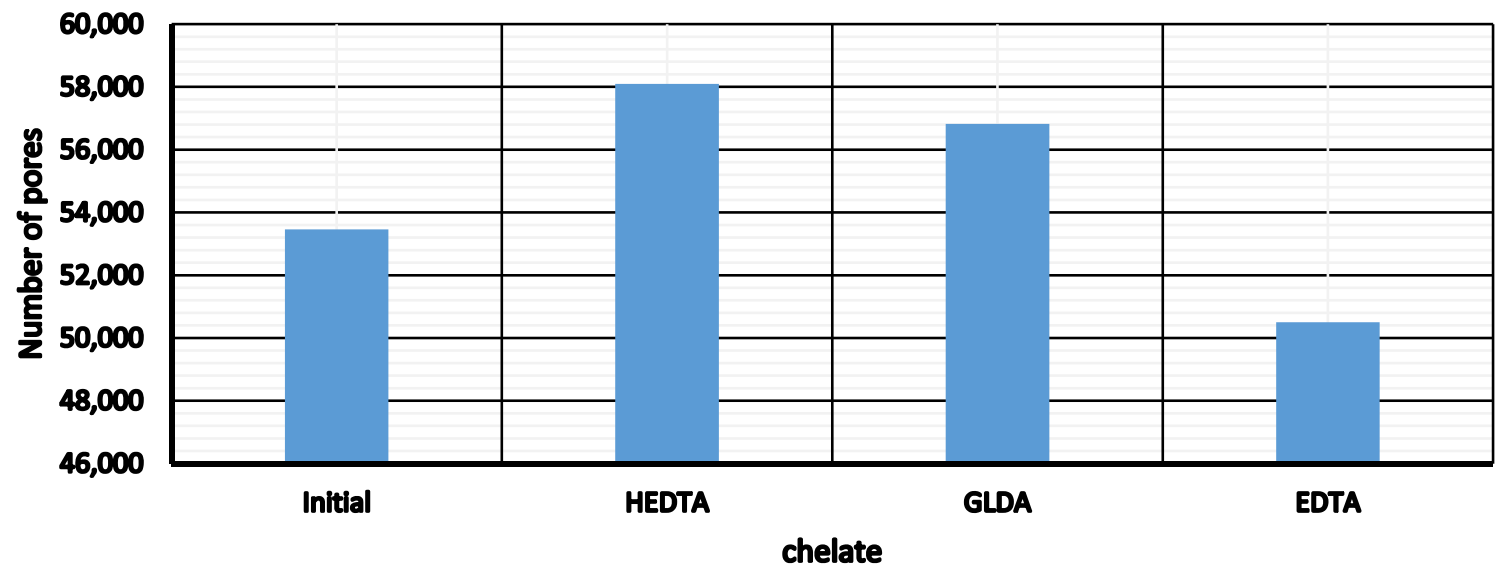

Fig. 3 Change in Number of pore space (Colton)

Table 6 Colton sandstone Initial and final pore size distribution

\begin{tabular}{llllllll}
\hline $\begin{array}{l}\text { Pore size } \\
\text { range }(\mu \mathrm{m})\end{array}$ & Initial & EDTA & \% change & HEDTA & \% change & GLDA & \% change \\
\hline $9.6-33$ & 52,590 & 49,095 & $-6.6 \%$ & 57,217 & $8.7 \%$ & 55,431 & $6.6 \%$ \\
$33-68$ & 862 & 1393 & $61.6 \%$ & 871 & $1.1 \%$ & 1,373 & $59.2 \%$ \\
$68-98$ & 5 & 17 & $240 \%$ & 7 & $40 \%$ & 16 & $220 \%$ \\
Total & 53,457 & 50,505 & $-5.5 \%$ & 58,095 & $8.6 \%$ & 56,820 & $6.3 \%$ \\
\hline
\end{tabular}




\section{Mineral relative mass $\%$}

The relative mineral mass analysis describes the dissolution of different minerals present in the sample. This analysis shows that the increment in porosity observed earlier due to the dissolution of what type of minerals. It also shows the chelating power of different chelates towards different ions.

\section{Berea}

In the case of Berea sandstone (Fig. 4), HEDTA showed chelating power towards albite, and orthoclase as a decrease in relative mass of these minerals has been observed. All the chelates showed good chelating power towards zircon, magnetite, pyrite, and rutile.

\section{Colton}

In the case of Colton sandstone (Fig. 5), HEDTA showed chelating power towards calcite and dolomite as a decrease in relative mass of these minerals was observed. EDTA and GLDA showed good chelating power towards albite and dolomite.

The mineral mass percentage changes showed the dissolution and precipitation of minerals in the core samples during reaction where different chelates showed dissolution power towards different minerals. In the next section, panorama analysis showed that there is an increment of pores and dissolution of minerals when chelating agents applied on all core samples.

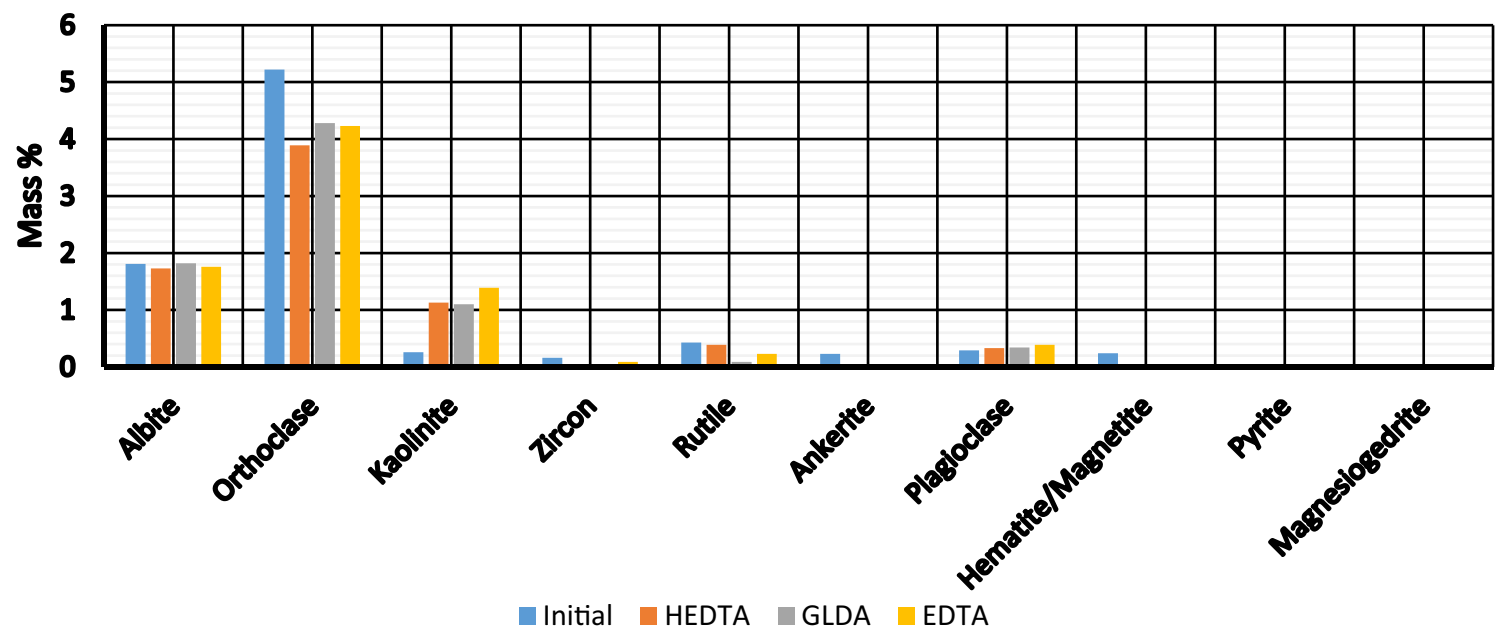

Fig. 4 Changes in mineral mass of conventional sandstone

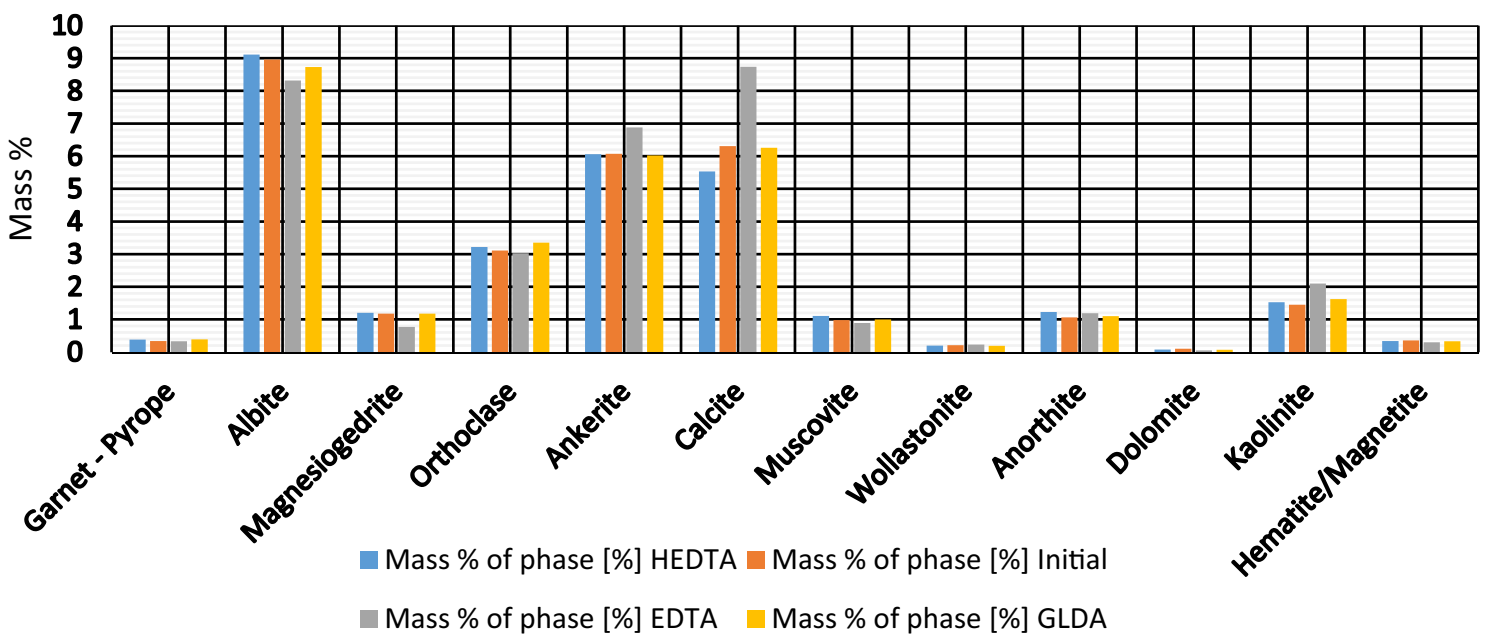

Fig. 5 Changes in mineral mass of tight sandstone 


\section{Panorama analysis}

This analysis was applied to present the panorama highquality BSE images (Black Scattered Electron) of the core samples. The presence of different minerals and rock matrix before and after acidizing on the core sample surface can be analyzed using this technique (Ward et al. 2017). The dissolution of minerals present in the core sample can be observed in Figs. 6, 7, 8, 9, 10, 11.

\section{Grain size distribution}

\section{Berea}

The number of grains of different important minerals before and after acidizing is discussed from Figs. 12, 13, 14, 15. The number of grains of ankerite, calcite, hematite/magnetite, and rutile was changed significantly after the reaction. It illustrated that these minerals have been dissolved by the chelates. These results can be validated by the mineral mass analysis presented earlier.
Fig. 6 a Panorama of initial Berea. b Panorama of Berea reacted with HEDTA

Fig. 7 a Panorama of initial Berea. b Panorama of Berea reacted with EDTA

Fig. 8 a Panorama of initial Berea. b Panorama of Berea reacted with GLDA

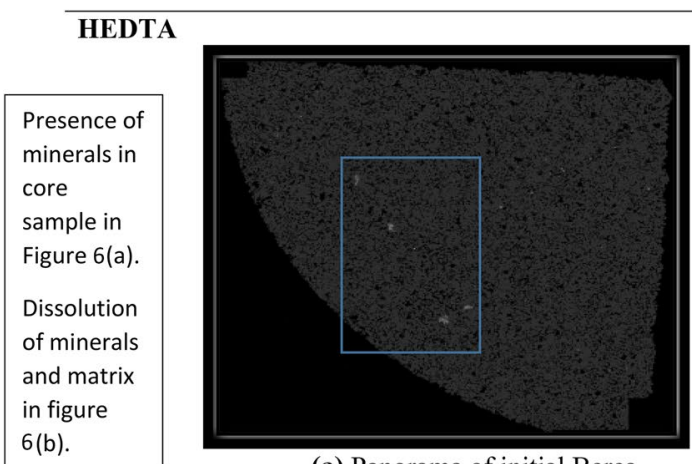

(a) Panorama of initial Berea

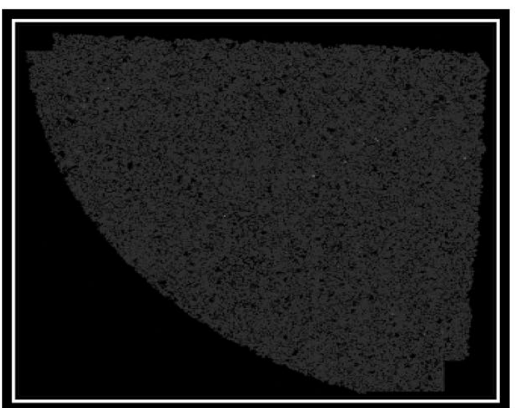

(b) Panorama of Berea reacted with HEDTA

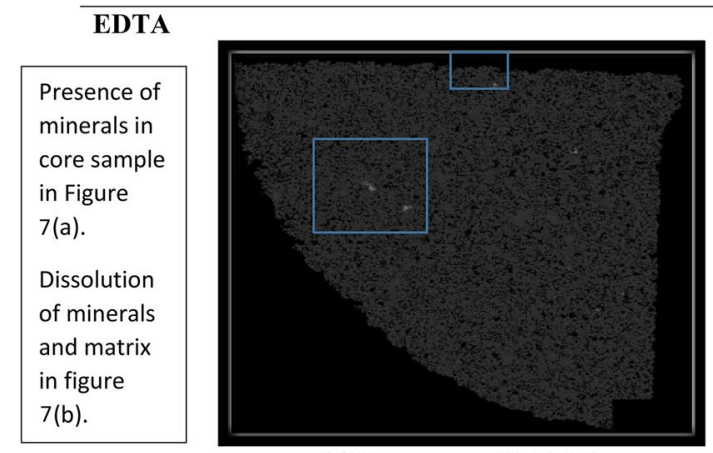

(a) Panorama of initial Berea

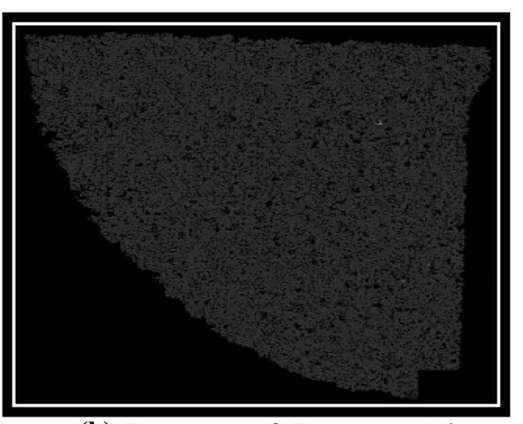

(b) Panorama of Berea reacted with EDTA

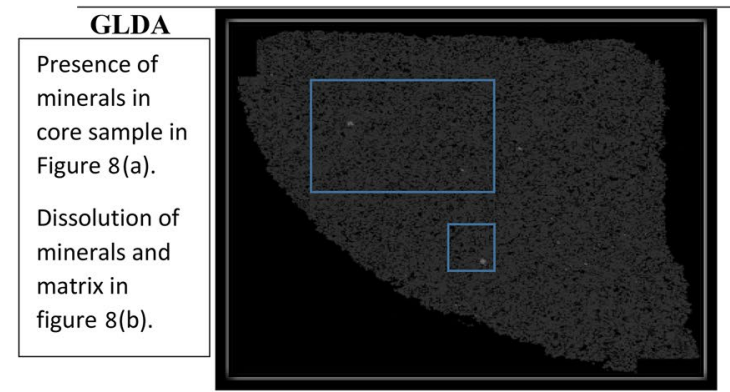

(a) Panorama of initial Berea

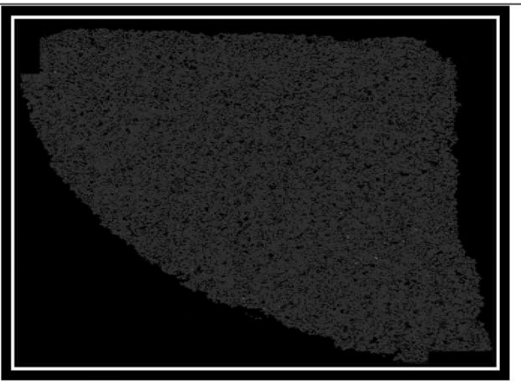

(b) Panorama of Berea reacted with GLDA 
Fig. 9 a Panorama of initial Colton. b Panorama of Colton reacted with HEDTA

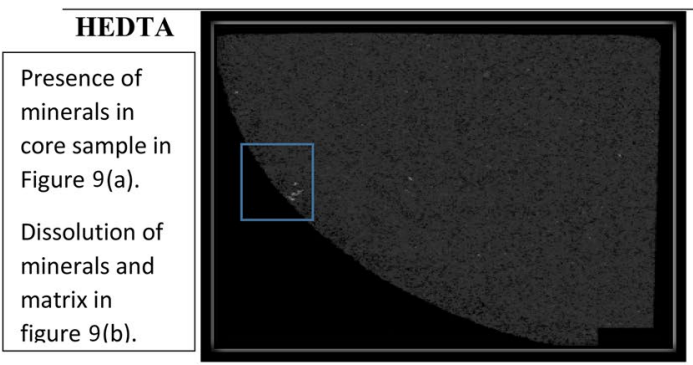

(a) Panorama of initial Colton

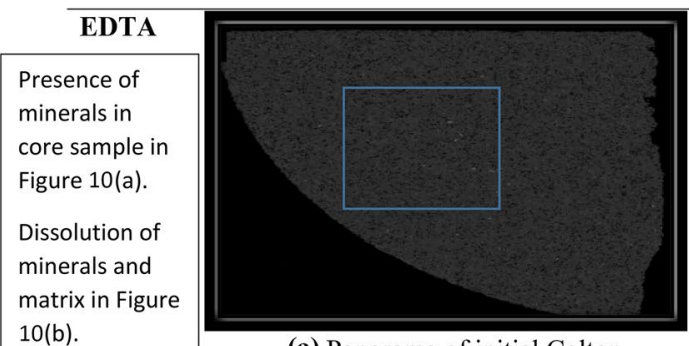

(a) Panorama of initial Colton

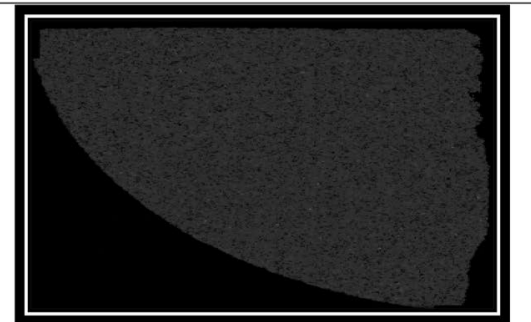

(b) Panorama of Colton reacted with EDTA

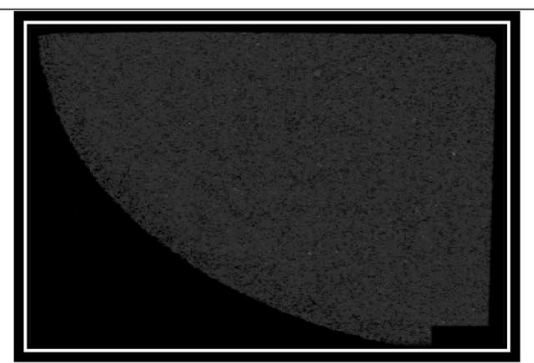

(b) Panorama of Colton reacted with HEDTA

Fig. 11 a Panorama of initial Colton. b Panorama of Colton reacted with GLDA

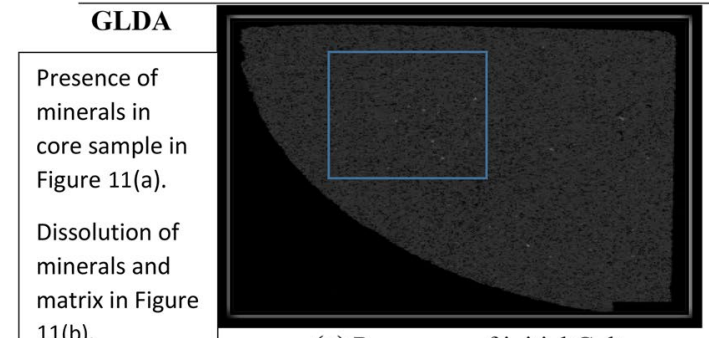

(a) Panorama of initial Colton

Fig. 10 a Panorama of initial Colton. b Panorama of Colton reacted with EDTA

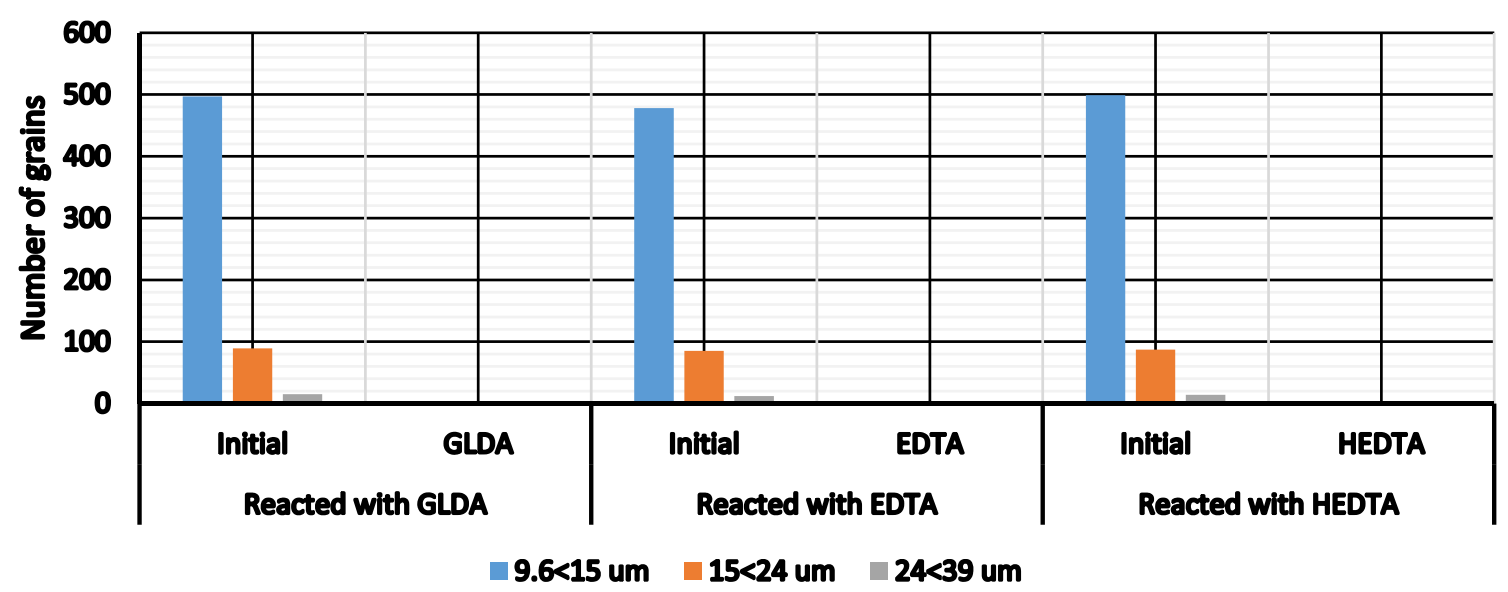

Fig. 12 The grain size distribution of Ankerite in Berea Sandstone before and after reaction with chelating agents 


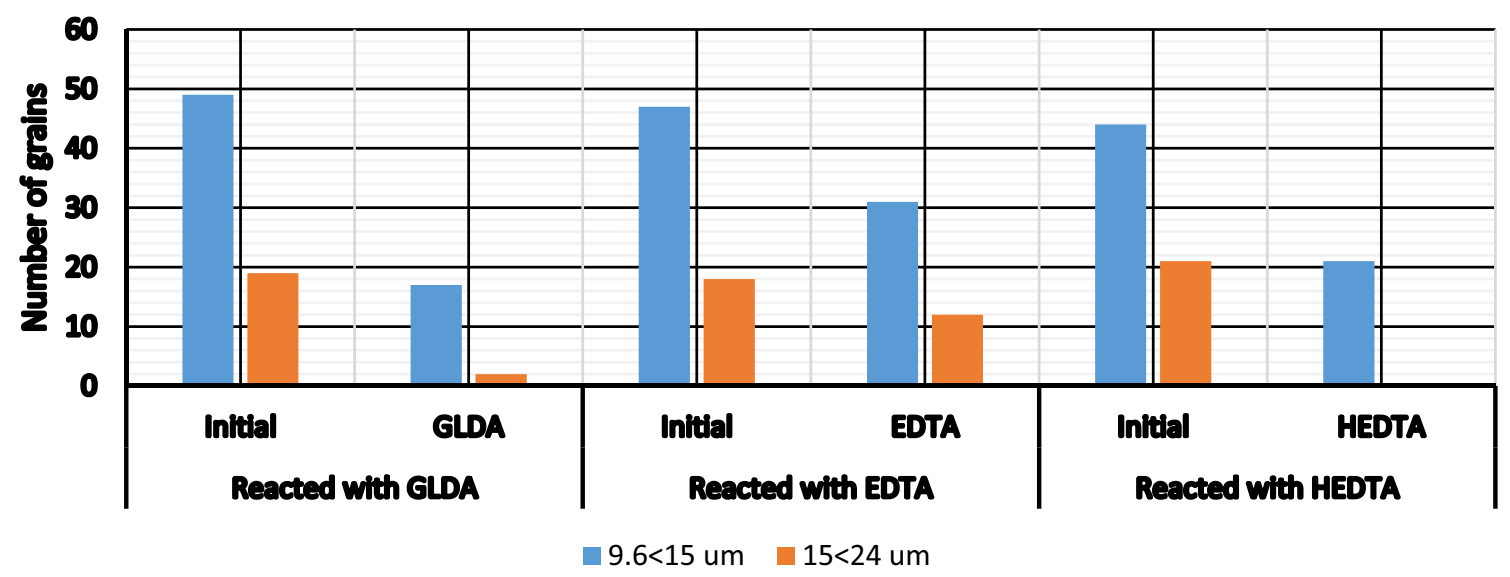

Fig. 13 The grain size distribution of Calcite in Berea Sandstone before and after reaction with chelating agents

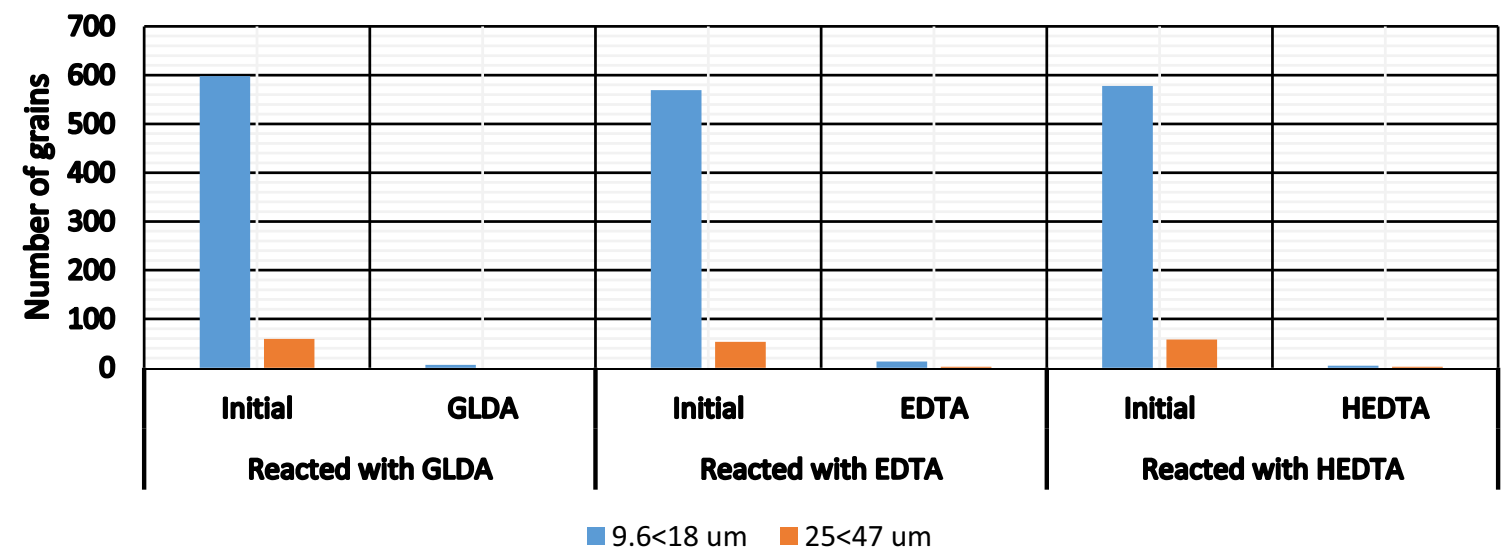

Fig. 14 The grain size distribution of Magnetite in Berea Sandstone before and after reaction with chelating agents

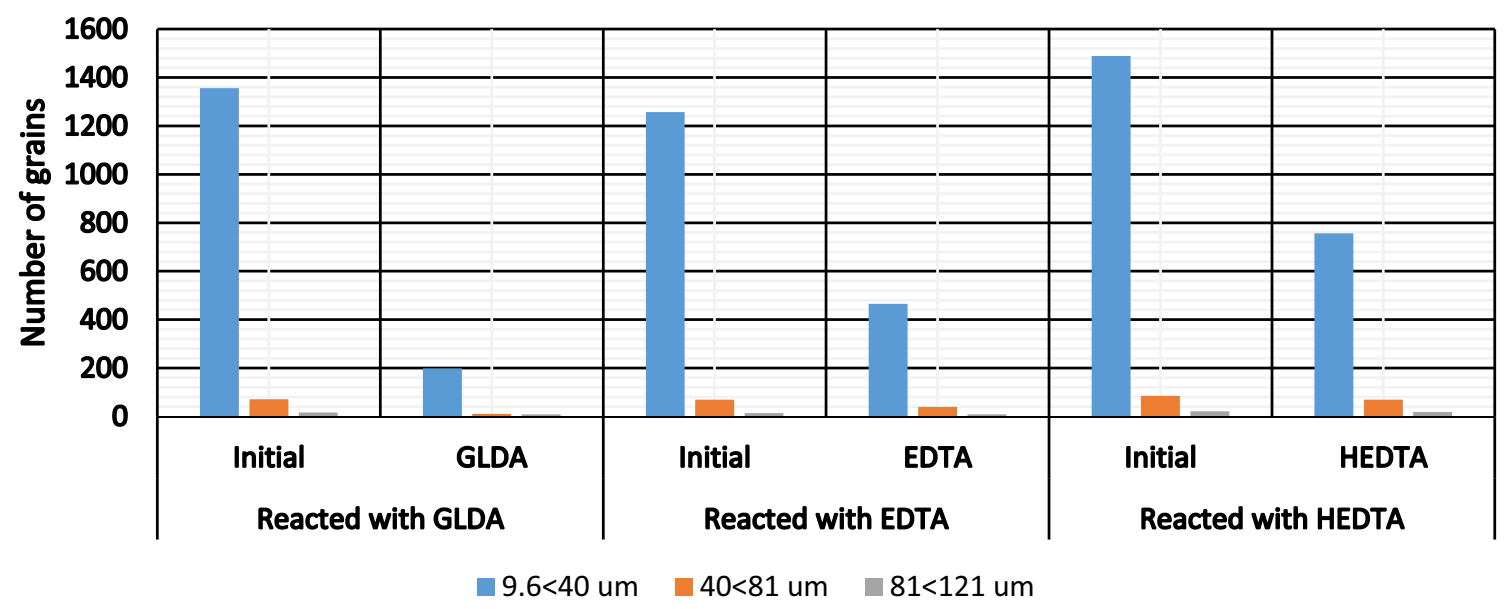

Fig. 15 The grain size distribution of Rutile in Berea Sandstone before and after reaction with chelating agents 


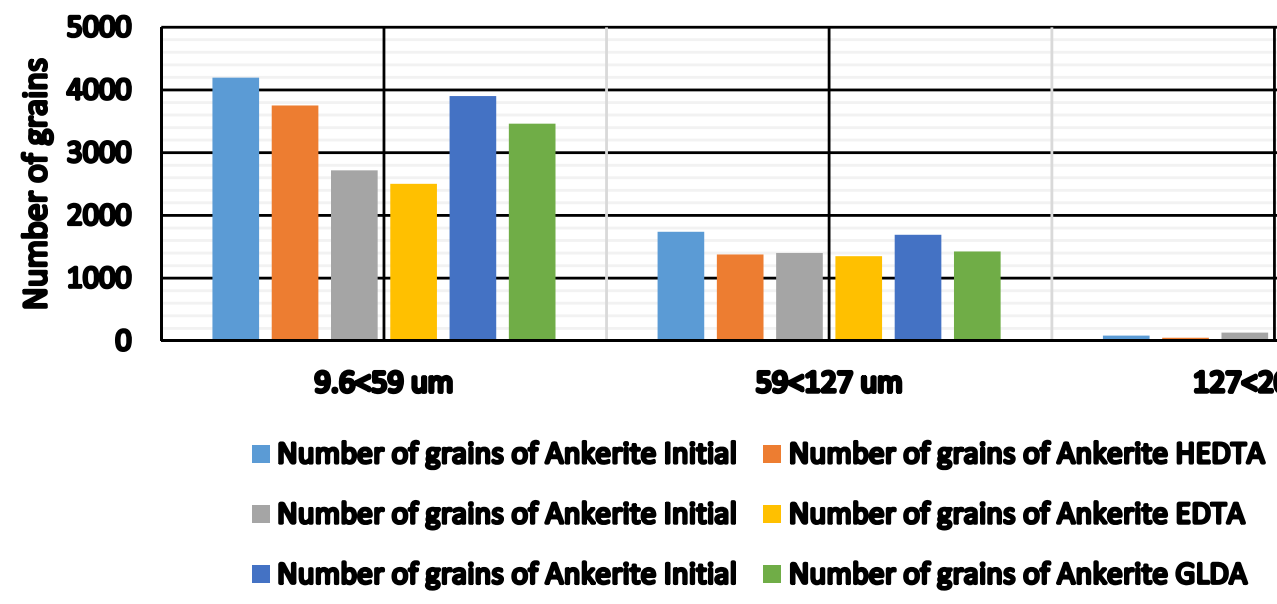

Fig. 16 The grain size distribution of ankerite in Colton Sandstone before and after reaction with chelating agents
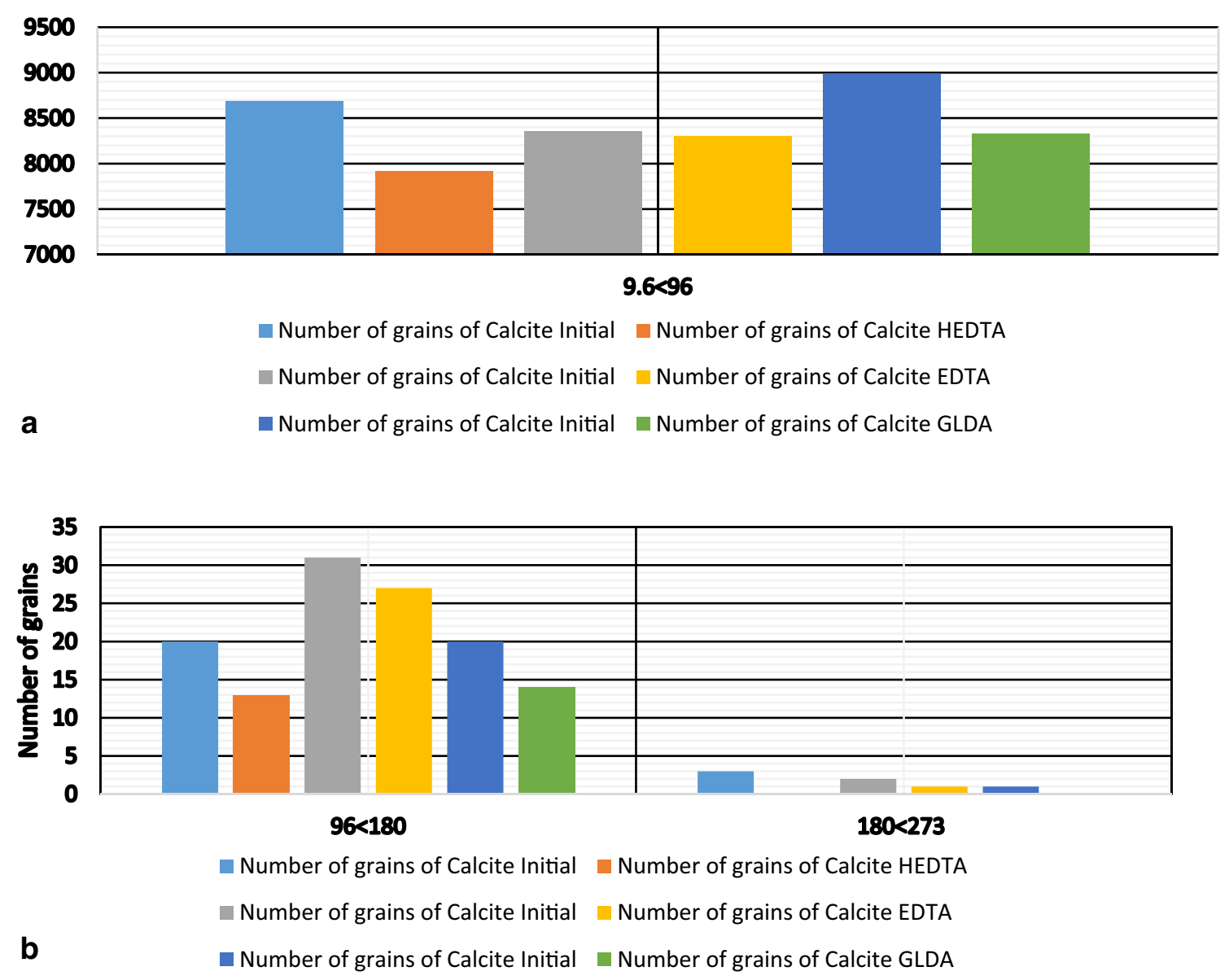

Fig. 17 The grain size distribution of calcite in Colton Sandstone before and after reaction with chelating agents

\section{Colton}

The number of grains of different important minerals before and after acidizing was discussed in Figs. 16 and 17. The number of grains of ankerite (Fig. 16) and calcite (Fig. 17) was changed significantly after reacting with GLDA and HEDTA. It indicated that these minerals dissolved when chelates were applied. This validates the results discussed earlier in the mineral mass analysis. 


\section{Particle density}

\section{Berea}

Particle density distribution represents the number of particles in a certain density range presented in Figs. 18. The sample acidized was Berea sandstone, while the density of sandstone was around $2.65 \mathrm{~g} / \mathrm{cm}^{3}$ as shown in Fig. 18b. The power of these agents in dissolving light particles like orthoclase (density $2.56 \mathrm{~g} / \mathrm{cm}^{3}$ ) was not effective as shown in Fig. 18a where the change in the number of light/less dense particles was less. On the other hand, heavy particles like ankerite $\left(2.97 \mathrm{~g} / \mathrm{cm}^{3}\right)$ and rutile $\left(4.2 \mathrm{~g} / \mathrm{cm}^{3}\right)$ were dissolved effectively as shown in Fig. 18c.

\section{Colton}

As for Colton sandstone, the density of sandstone was around $2.65 \mathrm{~g} / \mathrm{cm}^{3}$. Figure $19 \mathrm{~b}$ shows that most of the particle sizes were in the range of $2.4<2.8 \mathrm{~g} / \mathrm{cm}^{3}$. The power of these agents in dissolving light particles like orthoclase was not effective (Fig. 19a) where the change in the number of light/less dense particles was less. On the other hand, a heavy particle such as ankerite $\left(2.97 \mathrm{~g} / \mathrm{cm}^{3}\right)$ was dissolved effectively as shown in Fig. 19c.

Figures 19a illustrated that some amount of heavy particles ranged from $3.7<10 \mathrm{~g} / \mathrm{cm}^{3}$ were dissolved during acidizing with these chelates especially when reacted with HEDTA. Likewise, Fig. 19c depicted that minerals in the range of $2.8<3.7 \mathrm{~g} / \mathrm{cm}^{3}$ were dissolved effectively by all chelates. To summarize, all of these applied chelates dissolved a large number of particles in each density range.
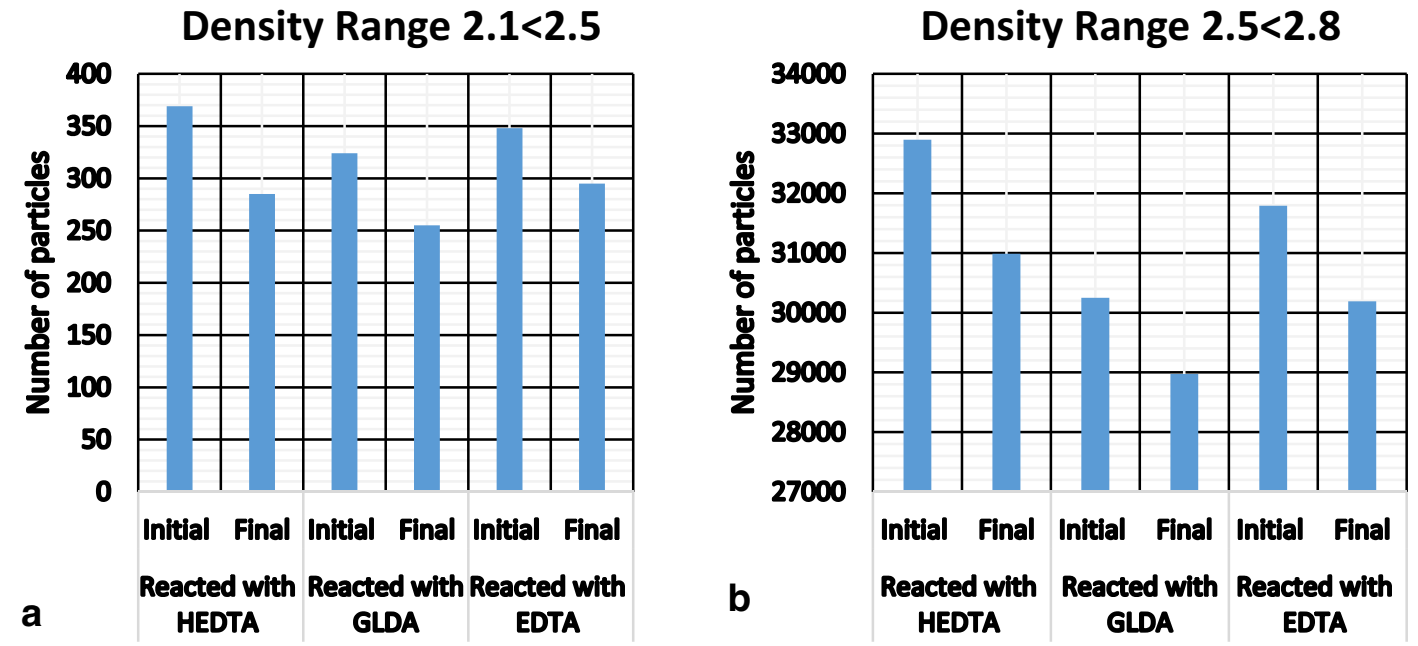

Density Range $2.8<6.4$

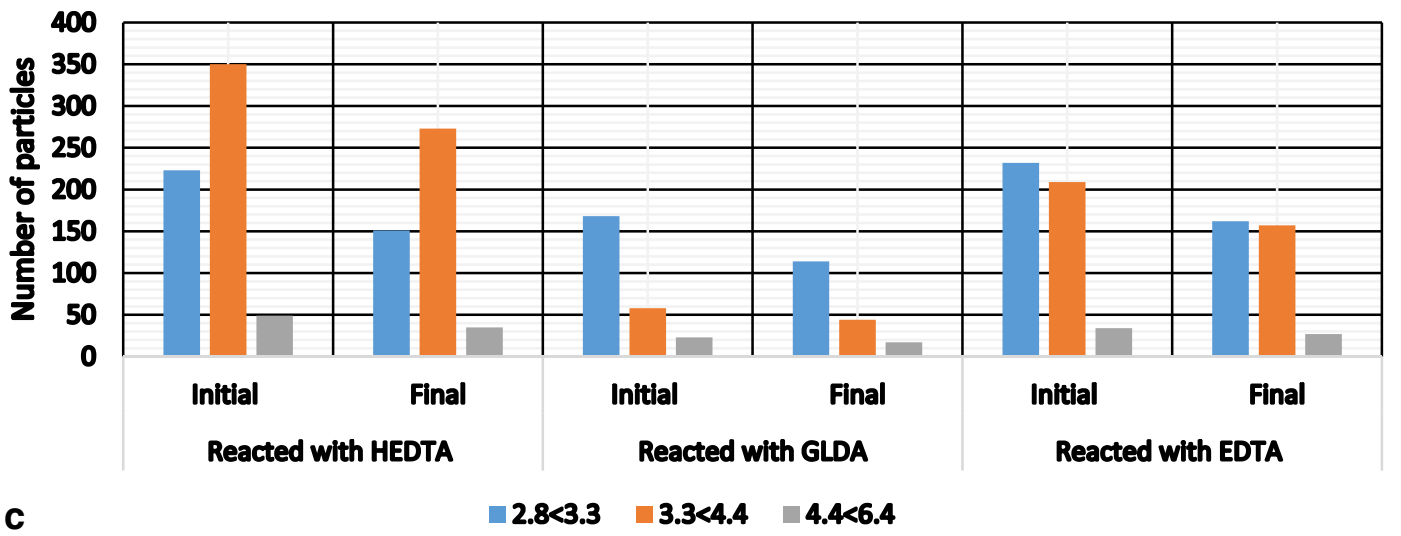

Fig. 18 Particle density distribution in Berea Sandstone before and after reaction with chelating agents 


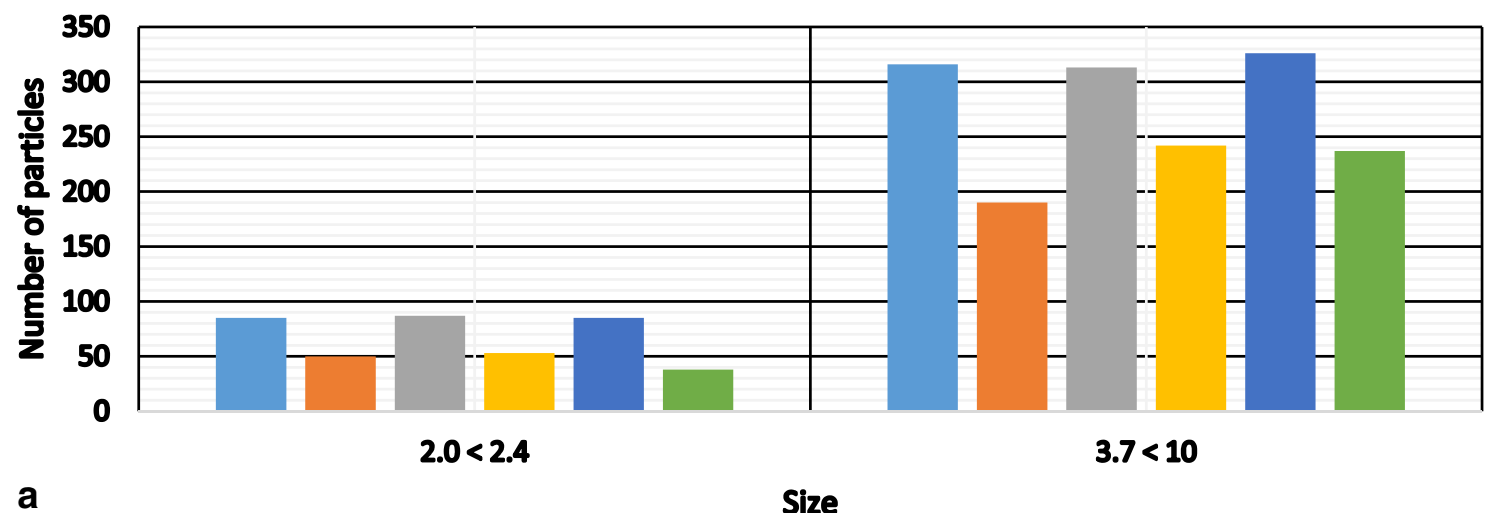

- Initial $\square$ HEDTA initial EDTA Initial $\square$ GLDA

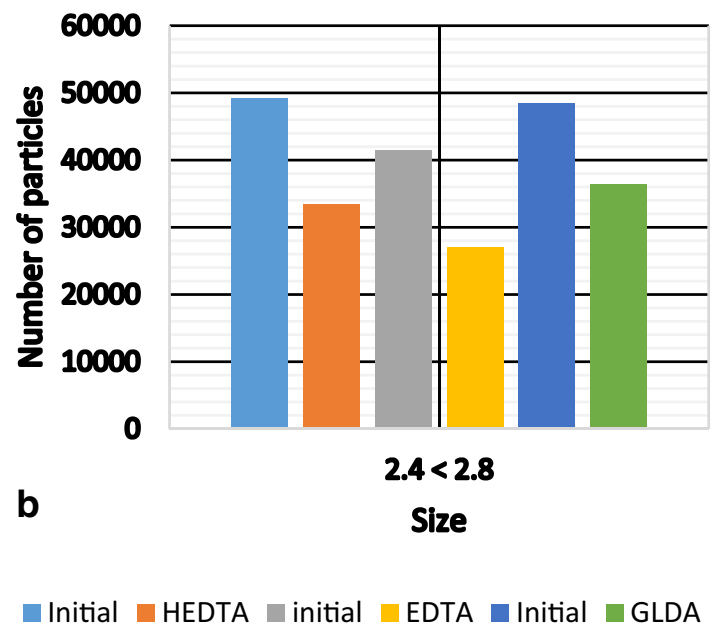

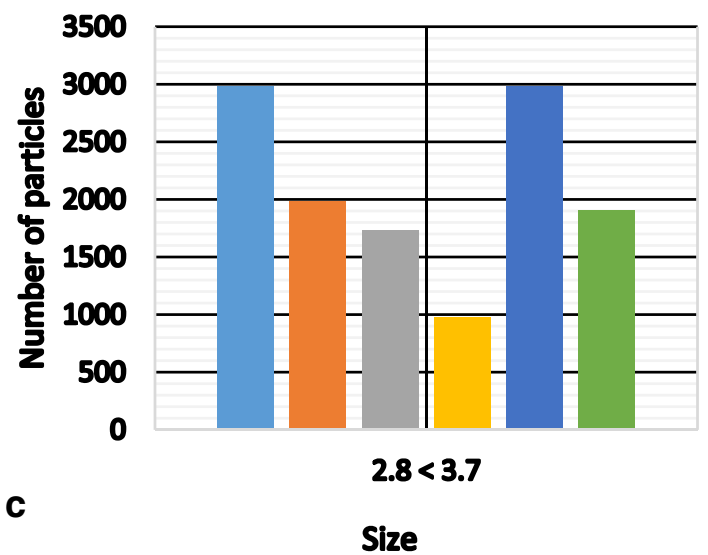

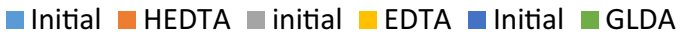

Fig. 19 Particles density distribution in Colton Sandstone before and after reaction with chelating agents

\section{Conclusion}

The study presented the behavior of different chelating agents reacting with different types (conventional and tight) of sandstones. The study provided a comprehensive experimental data that can be used to analyze changes occurring, after stimulation with chelating agents at high temperatures.

The results showed that HEDTA was the most effective chelating agents, among the chelating agents used for both conventional (Berea) and tight (Colton) sandstones. On the other hand, GLDA was comparatively less effective in terms of increasing permeability and porosity, but the numbers of pore spaces created were lesser as compared to EDTA. The least enhancement in permeability and porosity values was observed in the case of Berea when EDTA was used, resulting from choking of pore throats due to precipitation. TIMA analysis showed that HEDTA was effective in the dissolution of quartz, calcite, and dolomite. GLDA was effective in chelating zircon and rutile and EDTA was effective in dissolving orthoclase, zircon, and rutile.

This study can be used for sandstone acidizing, by using chelating agents for high-temperature conditions. It will also help to design effective acid mixtures depending on the mineralogical composition of the target sandstone formation.

Acknowledgements First of all, thanks to JDLC Centre, Curtin Australia for their support in utilizing the TIMA machine. The TESCAN Integrated Mineral Analysis (TIMA) instrument was funded by a Grant from the Australian Research Council (LE140100180) and is operated by the John de Laeter Centre at Curtin University with the support of the Geological Survey of Western Australia, University of Western Australia and Murdoch University.

Open Access This article is licensed under a Creative Commons Attribution 4.0 International License, which permits use, sharing, adaptation, distribution and reproduction in any medium or format, as long as you give appropriate credit to the original author(s) and the source, provide a link to the Creative Commons licence, and indicate if changes were made. The images or other third party material in this article are 
included in the article's Creative Commons licence, unless indicated otherwise in a credit line to the material. If material is not included in the article's Creative Commons licence and your intended use is not permitted by statutory regulation or exceeds the permitted use, you will need to obtain permission directly from the copyright holder. To view a copy of this licence, visit http://creativecommons.org/licenses/by/4.0/.

\section{References}

Al Mubarak T, Jun HN, Hisham NED (2017) Oilfield scale removal by chelating agents: an aminopolycarboxylic acids review. https ://doi.org/10.2118/185636-MS

Frenier WW (2001) Novel scale removers are developed for dissolving alkaline earth deposits. https://doi.org/10.2118/65027-MS

Kolodynska D, Jachula J, Hubicki Z (2009) MGDA as a new biodegradable complexing agent for the sorption of heavy metal ions on an anion exchanger. In: International symposium on physical-chemical methods of the mixture separation-Ars Septoria. Kudowa, Zdroj

Leong VH, Mahmud HK, Law MC (2018) A numerical modelling and simulation of core-scale sandstone acidizing process: a study on the effect of temperature. J Petrol Explor Prod Technol. https:// doi.org/10.1007/s13202-018-0522-8

Mahmoud M (2017) New formulation for sandstone acidizing that eliminates sand production problems in oil and gas sandstone reservoirs. J Energy Resour Technol. https://doi.org/10.1115/1.40365 21

Mahmud HK, Leong VH (2017) A comparative study of different acids used for sandstone acid stimulation: a literature review. IOP Conf Ser Mater Sci Eng. https://doi.org/10.1088/1757899X/217/1/012018

Martell AE, Smith RM, Motekaitis RJ (2004) NIST critically selected stability constants of metal complexes databases. Texas A\&M University, Texas

Nianyin L, Zhang Q et al (2015) A new multichelating acid system for high-temperature. J Chem. https://doi.org/10.1155/2015/594913

Schuler PJ, Wang KS, Dunn KL et al (2002) Effects of scale dissolvers on barium sulfate deposits: a macroscopic and microscopic study. CORROSION. Denver, Colorado
Shafiq MU, Ben Mahmud HK (2017) Sandstone matrix acidizing knowledge and future development. J Petrol Explor Prod Technol. https://doi.org/10.1007/s13202-017-0314-6

Shafiq MU, Mahmud HK, Rezaee R, Testamanti N (2017) Investigation of changing pore topology and porosity during matrix acidizing using different chelating agents. IOP Conf Ser Mater Sci Eng. https://doi.org/10.1088/1757-899X/217/1/012023

Shafiq MU, Ben Mahmud HK, Arif M (2018a) Mineralogy and pore topology analysis during matrix acidizing of tight sandstone and dolomite formations using chelating agents. J Pet Sci Eng 167:869-876

Shafiq MU, Chong YJ, Mahmud HKB (2018b) Application of emulsified acids on sandstone formation at elevated temperature conditions: an experimental study. J Petrol Explor Prod Technol. https ://doi.org/10.1007/s13202-018-0567-8

Shafiq MU et al (2018c) Integrated mineral analysis of sandstone and dolomite formations using different chelating agents during matrix acidizing. Petroleum. https://doi.org/10.1016/j.petlm.2018.07.002

Shafiq MU, Chong YJ, Mahmud HKB, Hossain MM, Rezaee R, Testamanti N (2019a) Application of emulsified acids on sandstone formation at elevated temperature conditions: an experimental study. J Petrol Explor Prod Technol. https://doi.org/10.1007/s1320 2-018-0567-8

Shafiq MU, Mahmud HKB, Zahoor MK, Shahid ASA, Rezaee R, Arif M (2019b) Investigation of change in different properties of sandstone and dolomite samples during matrix acidizing using chelating agents. J Petrol Explor Prod Technol. https://doi.org/10.1007/ s13202-019-0683-0

Ward I, Merigot K, McInnes BIA (2017) Application of quantitative mineralogical analysis in archaeological micromorphology: a case study from barrow is., Western Australia. J Archaeol Meth Theor. https://doi.org/10.1007/s10816-017-9330-6

Publisher's Note Springer Nature remains neutral with regard to jurisdictional claims in published maps and institutional affiliations. 